\title{
Avaliação dos efeitos da suplementação com farinha de linhaça (Linum usitatissimum L.) marrom e dourada sobre o perfil lipídico e a evolução ponderal em ratos Wistar
}

\author{
MOLENA-FERNANDES, C.A. ${ }^{1 *}$; SCHIMIDT, G ${ }^{2}$; NETO-OLIVEIRA, E.R. ${ }^{2}$; BERSANI-AMADO, C.A. ${ }^{2}$; CUMAN, R.K.N. ${ }^{2}$ \\ ${ }^{1}$ Faculdade Estadual de Educação, Ciências e Letras de Paranavaí. Av. Gabriel Esperidião, s/n, CEP: 87703-000, \\ Paranavaí-Brasil *molena126@hotmail.com. 2Universidade Estadual de Maringá, Departamento de Farmácia e \\ Farmacologia, Laboratório de Inflamação, Avenida Colombo, 5690, CEP: 87020-900, Maringá-Brasil
}

\begin{abstract}
RESUMO: Neste trabalho foram comparados os efeitos da farinha de linhaça dourada e farinha de linhaça marrom sobre o perfil lipídico e evolução ponderal em ratos Wistar. Os animais foram divididos aleatoriamente em três grupos, Grupo Controle (GC); Grupo suplementado com Farinha de Linhaça Marrom (LM) e Grupo Suplementado com Farinha de Linhaça Dourada (LD). Os animais foram submetidos à avaliação ponderal em dias alternados até o dia do sacrifício, no 360 dia, quando amostras de sangue foram coletadas para avaliação do perfil lipídico. O uso da farinha de linhaça como suplemento dietético de ratos Wistar, no período de 35 dias, promoveu redução significativa dos níveis de triglicérides séricos e da razão CT/HDL-C, com concomitante aumento dos níveis séricos de HDL-c, demonstrando assim efeito cardioprotetor. Os efeitos sobre o incremento de massa corporal dos animais durante o período do experimento sugerem importante ação preventiva no desenvolvimento da obesidade para a farinha de linhaça.
\end{abstract}

Palavras-chave: farinha de linhaça marrom, farinha de linhaça dourada, perfil lipídico, peso corporal, ratos Wistar

\begin{abstract}
Evaluation of the effects of supplementation with brown and golden flax (Linum usitatissimum L.) flour on lipid profile and weight gain in Wistar rats. In this work, the effects of brown and golden flax flour were compared based on lipid profile and weight gain in Wistar rats. The animals were randomly divided into three groups: control group (CG); group supplemented with brown flax flour (BF); and group supplemented with golden flax flour (GF). The animals were subjected to weight assessment on alternate days until sacrifice at the $36^{\text {th }}$ day, when blood samples were collected for lipid profile evaluation. The use of flax flour as dietary supplement to Wistar rats, in a 35-day period, led to a significant decrease in the serum levels of triglycerides and TC:HDL-C ratio, with concomitant increase in HDL-C serum levels, demonstrating thus a cardioprotective effect. The effects on rat weight gain over the experimental period suggest an important preventive action of flax flour on the obesity development.
\end{abstract}

Key words: brown flax flour, golden flax flour, lipid profile, body weight, Wistar rats

\section{INTRODUÇÃO}

As doenças crônicas representam a principal causa de mortalidade e incapacidade no mundo inteiro, principalmente as doenças cardiovasculares (DCV), obesidade, câncer, diabetes, hipertensão e doenças respiratórias.

Dentre os fatores de risco destas doenças podem ser citados os excessos de LDL-colesterol (LDL-C) e de triglicérides (TG) séricos, redução dos níveis de HDL-colesterol (HDL-c) sérico, a presença de Síndrome Metabólica, e outros (Prased, 2005; Moreira et al., 2006). Alguns componentes ou fatores dietéticos têm sido associados à redução desses fatores de risco, por exemplo, ácidos graxos monoinsaturados (AGMI), ácidos graxos poliinsaturados Ômega 3 e Ômega 6 (AG- $\omega 3$ e AG$\omega 6)$, flavonóides, vitaminas e minerais com ação antioxidante (A, C, E, Se), lignanas, e um elevado consumo de frutas, verduras e alimentos integrais (Moreira et al., 2006; Nagao \& Yanagita, 2008).

Pesquisas têm demonstrado ainda uma redução da taxa de mortalidade para esse grupo de doenças após o uso de ácidos graxos poliinsaturados 
ômega 3 de cadeia longa (EPA, DHA) e de cadeia mais curta (Ácido $\alpha$-linolênico - ALA). Os prováveis mecanismos para o efeito cardioprotetor desses AG$\omega 3$ incluem efeitos anti-arrítmicos, antitrombóticos, antiinflamatórios, redução da pressão arterial, aumento da função endotelial, efeitos hipotrigliceridêmicos e retardo do crescimento das placas ateroscleróticas (Connor, 2000; Morise et al., 2004).

O ALA corresponde à forma vegetal dos AG$\omega 3$, sendo os óleos de soja e canola as principais fontes dietéticas, todavia a linhaça destaca-se como sendo a fonte vegetal mais rica nesse ácido graxo (Balk et al., 2006).

Apesar de ainda existirem controvérsias em relação aos mecanismos pelos quais o ALA exerce seus efeitos, potentes benefícios preventivos e/ou terapêuticos têm sido demonstrados em animais de laboratórios e seres humanos após o uso de linhaça e/ou derivados na dieta, aumentando a atenção da comunidade científica para o uso desta semente como alimento funcional (Coskuner \& Karababa, 2007; Vijaimohan et al., 2006).

Estudos têm apontado que a ingestão de pequenas quantidades de linhaça ao dia promove alterações hormonais contribuindo com a redução do risco de câncer e diabetes, dos níveis de colesterol total e LDL-c, assim como favorece a diminuição da agregação antiplaquetária (Pellizon et al., 2007; Ddodin et al., 2008). E, embora os estudos sejam escassos, a linhaça e os componentes parecem exercer efeito sobre o ganho de massa gorda e, portanto poderia ser utilizada para o controle da obesidade e do diabetes melittus tipo 2 (Bhatena \& Velasquez, 2002).

Como todos os vegetais, existem muitas variedades na mesma família. No que se refere à linhaça, a marrom e a dourada são as mais conhecidas. Ambas as variedades são praticamente idênticas nas propriedades nutricionais e terapêuticas sendo mínimas as diferenças, as quais, de um modo geral, são resultantes das condições de cultivo (Coskuner \& Karababa, 2007).

A linhaça dourada desenvolve-se em climas muito frios, como no Canadá (maior produtor mundial de linhaça) e norte dos Estados Unidos. A linhaça marrom pode desenvolver-se em regiões de clima quente e úmido, como é o caso do Brasil. A linhaça dourada apresenta índices de lignana superiores aos da linhaça marrom. Entretanto, ao contrário do que alegam os que comercializam a linhaça dourada, existe discreta vantagem para a linhaça marrom, que é 100\% nacional, em relação à quantidade de Omega 3 (Feng et al., 2003; Trucom, 2006).

Em abundância no Brasil, as sementes de cor marrom já foram acusadas de maior toxicidade e menor funcionalidade nutricional. Isso ocorre talvez por serem menos estudadas que as douradas, variedade que é consumida e pesquisada há mais tempo pelos maiores produtores mundiais do hemisfério norte (Trucom, 2006).

Diante disto, estudos para avaliar a diferença das duas linhaças são de extrema importância, principalmente considerando que a semente de linhaça marrom, cultivada no Brasil é vendida a preços bem mais acessíveis do que a linhaça dourada. Considerando então a inconsistência de dados científicos comparativos entre linhaça marrom e dourada, o presente estudo teve como objetivo comparar os efeitos da farinha de linhaça dourada $e$ farinha de linhaça marrom sobre o perfil lipídico e evolução ponderal em ratos Wistar.

\section{MATERIAL E MÉTODO}

\section{Animais utilizados}

Foram utilizados ratos machos, adultos, da linhagem Wistar, com oito semanas de vida, provenientes do biotério central da Universidade Estadual de Maringá (UEM). Durante todo o período experimental os animais foram mantidos no biotério do laboratório de inflamação do Departamento de Farmácia e Farmacologia (DFF/UEM), consumindo ração balanceada (marca Nuvilab) e água ad libitum, sob um ciclo constante de 12 horas de luz e 12 horas de escuro, em temperatura de $22 \pm 1^{\circ} \mathrm{C}$.

\section{Grupos experimentais}

Após período de três dias de adaptação, nas condições descritas, os ratos foram divididos aleatoriamente em três grupos: O grupo LM $(n=9)$ foi suplementado diariamente com farinha integral de linhaça marrom micronizada LINO LIVE ${ }^{\circledR}$ (Farinhas Integrais CISBRA Ltda., Panambi-RS), por meio de entubação orogástrica, utilizando seringa descartável de $1 \mathrm{~mL}$ e agulha de gavage $\left(0,40 \mathrm{~g} \mathrm{Kg}^{-1}\right.$ peso corporal) misturada com carboximetilcelulose (CMC) a $0,05 \%$. O grupo LD ( $n=7)$ foi suplementado diariamente com farinha integral de linhaça dourada micronizada LINO LIVE $^{\circledR}$ (Farinhas Integrais CISBRA Ltda., Panambi$\mathrm{RS})$, também por gavage $\left(0,40 \mathrm{~g} \mathrm{Kg}^{-1}\right.$ peso corporal) misturada com carboximetilcelulose (CMC) a 0,05\%. O grupo Controle $(n=12)$ recebeu diariamente $\mathrm{CMC}+$ solução salina $0,9 \%$, por via oral.

\section{Produtos testados}

Foram testadas dois tipos de farinhas de linhaça integral (marrom e dourada), da marca LINO LIVE $^{\circledR}$, comercializadas pela empresa de farinhas integrais CISBRA Ltda., situada em Panambi, Rio Grande do Sul. As duas farinhas fornecidas pela empresa eram de lote único (no 21207) e foram acondicionadas em embalagem de polipropileno e armazenadas em local e temperatura adequados para 
conservação. Para minimizar a oxidação das fontes lipídicas presente nas farinhas, a preparação das mesmas era realizada diariamente no momento da distribuição aos animais.

A composição química das farinhas, descritas na Tabela 1, foi realizada no Laboratório analítico habilitado pela ANVISA, Alac Garibaldi Garibaldi, RS e a produção das farinhas foi realizada seguindo as normas da resolução RDC no 263/2005 que aprova o Regulamento técnico para produtos de cereais, amidos, farinhas e farelos no Brasil (Brasil, 2005).

As farinhas utilizadas neste estudo são produzidas a partir da semente de linhaça, também conhecida como linho, pertencente à família Linaceae, do gênero Linum. A semeadura do linho utilizado neste estudo foi feita na região sul no início de Junho. A densidade de semeadura empregada foi de 800 a 1000 sementes por $\mathrm{m}^{-2}$, e aumentando esta densidade conforme o atraso no plantio. O plantio é realizado com máquina semeadora utilizada para trigo, com espaçamentos entre linhas de 15 a $20 \mathrm{~cm}$, e a profundidade de 1 a $2 \mathrm{~cm}$. A cultura do linho está pronta para colheita quando os grãos apresentam umidade próxima a 10\%.

As sementes são cultivadas sem o uso de agrotóxicos e fertilizantes químicos, utilizando práticas e estratégias de produção voltadas para a manutenção dos recursos naturais e a garantia da segurança alimentar. Partindo desse princípio a CISBRA utiliza alternativas consideradas ambientalmente corretas para a produção da matéria prima sendo que uma das alternativas encontradas tem sido o uso de fertilizante orgânico. O processo de produção do fertilizante orgânico é fiscalizado pelo Ministério da Agricultura e pelo órgão ambiental competente. O controle de qualidade é realizado periodicamente, através de amostras que são enviadas ao laboratório credenciado pelo Ministério da Agricultura.

A linha de produção das farinhas de linhaça inicia-se com o recebimento dos grãos de linhaça dourada e marrom, que são inspecionados e analisados quanto a parâmetros de qualidade física, química e biológica. Após inspeção e análise os grãos são encaminhados para o armazenamento. Nesta etapa os grãos são mantidos em sacarias sob condições adequadas de higiene (sobre pallets, afastado da luz solar, distanciado das paredes), sob temperatura ambiente, livre de acesso de insetos e roedores.

Posteriormente, os grãos são submetidos ao processo de secagem, por tratamento térmico a $72^{\circ} \mathrm{C}$ por 8 minutos aproximadamente, com a finalidade de reduzir a umidade do grão. Os grãos após etapa de secagem são levados para classificação em mesa de gravidade para retirada de algum possível fragmento físico, sendo acondicionados em sacarias previamente inspecionadas. Após classificação os grãos são encaminhados para o armazenamento sobre pallets distantes das paredes, a temperatura ambiente, atendendo as normas estabelecidas pelas Boas Práticas de Fabricação, RDC № 275, de 2002 (ANVISA).

TABELA 1. Composição química das farinhas de linhaça marrom e dourada.

\begin{tabular}{|c|c|c|}
\hline & \multicolumn{2}{|c|}{ g $15 \mathrm{~g}^{-1}$ de Farinha } \\
\hline & Farinha de Linhaça Marrom & Farinha de Linhaça Dourada \\
\hline Carboidratos & $1,3 \mathrm{~g}$ & $2,2 \mathrm{~g}^{*}$ \\
\hline Proteínas & $2,5 \mathrm{~g}$ & $2,9 \mathrm{~g}$ \\
\hline Gorduras Totais & $3,3 \mathrm{~g}$, das quais: & $4,8 \mathrm{~g}$, das quais: \\
\hline Gorduras Saturadas & $0,5 \mathrm{~g}$ & $0,3 \mathrm{~g}$ \\
\hline Gorduras Trans & $0 \mathrm{~g}$ & $0 \mathrm{~g}$ \\
\hline $\begin{array}{c}\text { Gorduras Monoinsaturadas } \\
\text { Ômega-9 }\end{array}$ & $\begin{array}{c}0,7 \mathrm{~g} \text {, das quais: } \\
0,7 \mathrm{~g}\end{array}$ & $\begin{array}{c}0,9 \mathrm{~g}, \text { das quais: } \\
0,9 \mathrm{~g}^{*}\end{array}$ \\
\hline $\begin{array}{c}\text { Gorduras Poliinsaturadas } \\
\text { Ômega-3 } \\
\text { Ômega-6 }\end{array}$ & $\begin{array}{c}2,3 \mathrm{~g} \text {, das quais: } \\
1,8 \mathrm{~g} \\
0,5 \mathrm{~g}\end{array}$ & $\begin{array}{c}3,4 \mathrm{~g}, \text { das quais: } \\
2,8 \mathrm{~g}^{*} \\
0,6 \mathrm{~g}\end{array}$ \\
\hline Fibra Alimentar & $6,0 \mathrm{~g}$ & $3,8 \mathrm{~g}^{*}$ \\
\hline Sódio & $0 \mathrm{mg}$ & $1,0 \mathrm{mg}$ \\
\hline
\end{tabular}

*Diferença significativa entre as farinhas para $p<0,05$ (' $t$ ' de Student)

Rev. Bras. Pl. Med., Botucatu, v.12, n.2, p.201-207, 2010. 
No processo de moagem os grãos são despejados em moega a granel e elevados para silo pulmão situado sobre reator, de onde através de válvula automática são liberados para o interior deste reator hermético, onde recebem mais $8 \%$ de umidade, em forma de vapor d'água, sendo desta forma aquecido para fazer cocção e inativação, o que o torna mais digestivo. Em seguida, os grãos passam pelo sistema turbo dryer a vácuo, ainda neste mesmo reator, para melhor secagem e extração do excesso de umidade, juntamente com as possíveis toxinas (cianogênicos, linamarina, etc.); na sequência, é efetuada a micronização, no qual os grãos são submetidos à moagem, até atingir a granulometria desejada e por último já em forma de farinha, o produto é embalado.

Após a moagem, a farinha segue para salas de expurgo onde recebe tratamento químico, através da aplicação do "Gás Toxin", que elimina todo e qualquer tipo de ovos, larvas e insetos já adultos. A farinha é deixada por aproximadamente 72 horas exposta a este gás. Por último a farinha é encaminhada para pesagem e armazenamento em embalagens inspecionadas atendendo as normas de Boas Praticas de Fabricação.

\section{Avaliação ponderal e determinação do perfil lipídico}

Durante todo o procedimento experimental a massa corporal dos animais foi monitorada a cada 48 horas para determinação do incremento da massa corporal em gramas. Esta avaliação ponderal foi realizada através da pesagem dos animais em balança semi-analítica eletrônica até o 36일. quando os animais foram sacrificados e amostras de sangue foram coletadas para realização das análises bioquímicas. Alíquotas de plasma foram submetidas à avaliação do perfil lipídico. O colesterol total (CT) foi determinado pelo método enzimático da colesteroloxidase (Gold Analisa ${ }^{\circledR}$ ). Para a dosagem do HDLcolesterol (HDL-c) foi utilizado o sistema para precipitação do colesterol HDL no soro (Gold Analisa ${ }^{\circledR}$ ) que utiliza o ácido fosfotúngstico e cloreto de magnésio para precipitação seletiva e quantitativa das lipoproteínas de muito baixa densidade (VLDL) e de baixa densidade (LDL). Após a centrifugação, HDL-C foi determinado no sobrenadante utilizando o mesmo método de dosagem do $C T$, já descrito. Os triglicérides (TG) foram determinados pelo método enzimático da glicerol-3-fosfato-oxidase (Gold Analisa ${ }^{\circledR}$ ). Todos os resultados foram expressos em $\mathrm{mg} \mathrm{dL}^{-1}$.

\section{Análise estatística e procedimentos éticos}

Os resultados foram expressos como média \pm erro padrão da média (epm) e analisados por meio do teste ' $t$ ' de Student e análise de variância (ANOVA) para múltiplas comparações, seguida do teste de Tukey. $p<0,05$ foi utilizado como nível de significância.
O projeto foi aprovado pelo Comitê de Conduta Ética no Uso de Animais em Experimentação (CEAE) da Universidade Estadual de Maringá (Parecer no 033/ 2007).

\section{RESULTADO}

Avaliação dos efeitos da suplementação com a farinha de linhaça marrom (LM) e dourada (LD) sobre o perfil lipídico

A suplementação da dieta dos ratos com farinha de linhaça por um período de 35 dias promoveu redução significativa dos níveis de TG e no aumento significativo dos níveis de HDL-c em relação ao grupo controle, tanto no grupo $\operatorname{LM}(p<0,001)$ quanto no grupo LD $(p<0,01)$ (Tabela 2).

Avaliando os grupos que receberam suplementação, os níveis de HDL-c foram significativamente superiores no grupo LD em relação ao LM e, os níveis de TG séricos foram discretamente inferiores no grupo LD, indicando maior eficiência da linhaça dourada em relação à marrom em melhorar alguns parâmetros avaliados.

Os níveis médios de CT não diferiram significativamente entre os grupos, mas foi observado aumento médio de $52,42 \%$ e $84,94 \%$ nos níveis de HDL-c nos grupos LM e LD, respectivamente, em relação ao grupo Controle, indicando possivelmente que a suplementação levou à redução das lipoproteínas séricas de LDL-c e VLDL-c e, portanto, contribuiu ainda mais para a redução do risco de aterosclerose nesses animais.

Estas afirmações podem ser confirmadas por meio da significativa redução da razão CT/HDL-c dos grupos suplementados, LM $(1,78)$ e LD $(1,60)$, entre os quais foram verificadas em média, reduções de $35,27 \%$ e $41,82 \%$, respectivamente, em relação ao grupo controle $(2,75)$.

\section{Avaliação dos efeitos da suplementação com a farinha de linhaça marrom e dourada sobre o peso corporal}

$\mathrm{Na}$ avaliação ponderal dos animais suplementados e não suplementados com farinha de linhaça (Tabela 3) nenhuma diferença significativa foi observada no peso corporal inicial dos animais distribuídos entre os três grupos. Ao final do estudo, todos os animais tiveram aumento do peso corporal, sendo que entre aqueles suplementados com farinha de linhaça o ganho de peso foi significativamente menor ( $p<0,001)$ em relação ao grupo controle, que não recebeu suplementação. No grupo controle o peso médio dos animais foi mais de $40 \%$ superior ao dos grupos suplementados. Além disso, não foram verificadas diferenças significativas entre os dois grupos suplementados com farinha de linhaça marrom e dourada. 
TABELA 2. Perfil Lipídico dos animais suplementados com farinha de linhaça e controle.

\begin{tabular}{|c|c|c|c|c|}
\hline & Colesterol Total & HDL-C & Triglicérides & $\mathrm{CT} / \mathrm{HDL}-\mathrm{C}$ \\
\hline Animais & $\begin{array}{l}\text { Média } \pm \text { epm } \\
\left(\mathrm{mg} \mathrm{dL}^{-1}\right)\end{array}$ & $\begin{array}{l}\text { Média } \pm \text { epm } \\
\left(\mathrm{mg} \mathrm{dL}^{-1}\right)\end{array}$ & $\begin{array}{l}\text { Média } \pm \text { epm } \\
\left(\mathrm{mg} \mathrm{dL}^{-1}\right)\end{array}$ & $\begin{array}{l}\text { Média } \pm \text { epm } \\
\left(\mathrm{mg} \mathrm{dL}^{-1}\right)\end{array}$ \\
\hline Controle $(n=12)$ & $74,1 \pm 2,55$ & $26,9 \pm 1,19$ & $87 \pm 4,17$ & $2,75 \pm 0,41$ \\
\hline Farinha de Linhaça Marrom $(n=9)$ & $72,8 \pm 3,21$ & $41 \pm 3,04^{* *}$ & $66 \pm 4,04^{* *}$ & $1,78 \pm 0,22^{*}$ \\
\hline Farinha de Linhaça Dourada $(n=7)$ & $79,5 \pm 2,77$ & $49,75 \pm 0,41^{*} \#$ & $64,5 \pm 1,48^{\star}$ & $1,60 \pm 0,19^{*}$ \\
\hline
\end{tabular}

* Diferença significativa em relação ao controle $\left({ }^{*} p<0,001 ;{ }^{* *} p<0,01\right)$ - ANOVA \# Diferença significativa em relação ao Grupo LM ( $\left.p<0,05\right)$ - ANOVA epm = erro padrão da média

TABELA 3. Evolução Ponderal dos animais suplementados com farinha de linhaça e Controle.

\begin{tabular}{lccc}
\hline & \multicolumn{3}{c}{ Peso Corporal (g) } \\
\cline { 2 - 4 } & $\begin{array}{c}\text { Controle } \\
\text { Média } \pm \text { epm }\end{array}$ & $\begin{array}{c}\text { Linhaça marrom } \\
\text { Média } \pm \text { epm }\end{array}$ & $\begin{array}{c}\text { Linhaça dourada } \\
\text { Média } \pm \text { epm }\end{array}$ \\
Inicial (1 ${ }^{\circ}$ dia) & $204 \pm 2,53$ & $209,5 \pm 2,12$ & $206,5 \pm 3,90$ \\
Final (35이) & $333,8 \pm 6,38$ & $279,7 \pm 10,03^{*}$ & $283,5 \pm 7^{*}$ \\
$\Delta$ percentual & $+63,62 \%$ & $+33,5 \%$ & $+37,3 \%$ \\
\hline
\end{tabular}

* Diferença significativa em relação ao grupo controle para $p<0,001$ (ANOVA). epm = Erro Padrão da Média

\section{DISCUSSÃO}

A suplementação com as farinhas integrais de linhaça marrom e dourada promoveu melhora significativa no perfil lipídico dos animais avaliados. A redução observada nos níveis séricos dos triglicérides foi cerca de 3 vezes superior à verificada em ratos Wistar alimentados com farinha de linhaça (Prazad, 2001), e superior aquela verificada em coelhos suplementados com complexo de lignanas de linhaça (Prasad, 2005).

A partir destes resultados, pressupõe-se que, as farinhas de linhaça marrom e dourada, utilizadas neste estudo, apresentaram efeito benéfico no perfil lipídico destes animais, sendo este efeito mais acentuado com a administração da farinha dourada. Este fato possivelmente se deve a maior concentração de AG- $\omega 3$ e o AG- $\omega 9$ na farinha de linhaça dourada quando comparada a marrom (Tabela 1).

Elevados níveis de ácidos graxos insaturados parecem exercer papel importante na melhoria do perfil lipídico, tanto em humanos quanto em animais, sendo apontado efeito mais substancial na redução das lipoproteínas de baixa densidade (LDL), considerada fator de risco cardiovascular (Oohman, 2001; Morise et al., 2004).

O ácido graxo alfa-linolênico ( $A L A)$, pertencente ao grupo Ômega-3, está presente em cerca de $60 \%$ dos constituintes totais da linhaça, fazendo com que esta semente seja a maior fonte vegetal deste ácido graxo essencial, justificando o efeito superior encontrado na redução do colesterol em comparação a estudos realizados com outras fibras vegetais (Prazad, 2001; Bhatena \& Velasquez, 2002).

O uso da linhaça e derivados podem ainda estar associados com a redução do CT, LDL-c, TG e aumento do HDL-c por outros mecanismos, como o efeito laxativo das fibras. Estudos têm mostrado que, quando combinadas com uma dieta pobre em gorduras saturadas, as fibras diminuem o colesterol do sangue, reduzindo o risco de doenças do coração (Hemmings \& Barker, 2004; Cintra et al., 2006).

Apesar dos efeitos promovidos pelo consumo dos Omega-3, a quantidade ingerida deste ácido em quantidade excessiva pode influenciar a produção e função biológica as citocinas, cuja produção excessiva contribui para o desenvolvimento de diversas patologias. Além disso, o consumo aumentado dos ácidos graxos ômega-3 sem proteção antioxidante adequada pode levar a peroxidação lipídica in vivo e, portanto reduzir os efeitos benéficos, sendo necessária para minimizar estes riscos, a utilização de níveis apropriados de antioxidantes 
(Meydani, 1996).

Neste aspecto, a linhaça se destaca por conter, além da grande quantidade de ácidos graxos essenciais, propriedades antioxidantes, como os compostos fenólicos e as lignanas. Vários mecanismos têm sido sugeridos para explicar as ações antioxidantes das lignanas in vivo. A atividade antioxidante das lignanas na linhaça funcionaria inativando os radicais livres dos ácidos graxos e espécies reativas de oxigênio, como também tendo efeito indireto in vivo nos sistemas antioxidantes endógenos, como na enzima glutationa, por exemplo (Kinniry et al., 2006). Sendo assim, a linhaça, por vincular conteúdos de lignanas e omega 3 na composição, tem sido considerada alimento funcional de potente efeito antiaterogênico (Prasad, 2005).

Convém ressaltar ainda que, a dieta do tipo ocidental é deficiente em ácidos graxos Omega-3, a qual é refletida na taxa dietética de Omega- 6 para Omega-3 estimada atualmente em 20-25:1 (Arterburn et al., 2006), enquanto que o preconizado pela Organização Mundial da Saúde (1995) seria uma relação de 5-10:1. Neste aspecto, a linhaça aparece mais uma vez como alimento funcional de destaque, pois na composição a predominância de Omega-3 é três vezes superior ao Omega- $6(n-3 / n-6=3: 1)$, fato este que tem sido correlacionado com a prevenção de doenças coronarianas e alguns tipos de câncer (Coskuner \& Karababa, 2007).

Quanto aos efeitos promovidos pelo consumo das farinhas integrais de linhaça dourada e marrom sobre a evolução ponderal dos animais avaliados, os resultados obtidos neste estudo corroboram aqueles relatados por outros autores em pesquisas com roedores (Vijaimohan et al., 2006; Nagao \& Yanagita, 2008).

As características metabólicas dos AG são fortemente influenciadas pelo perfil geral das gorduras da dieta, o que resulta nas diferentes taxas de ganho de peso proporcionadas pelos diferentes AG ingeridos. Dentre estes, embora ainda existam limitações e controvérsias, aparentemente, os AGPI- $\omega 3$ protegem contra o ganho de peso, apresentando, portanto comportamento antiobesogênico (Pan \& Storlien, 1993).

A capacidade dos AGPI- $\omega 3$ reduzirem o ganho de massa corporal adiposa parece estar relacionada à oxidação preferencial desses $A G$, bem como à produção de "buracos" (Efeito leaky) na membrana que levariam ao aumento do gasto energético com concomitantes alterações nas taxas metabólicas (Aailhaud et al., 2006).

A capacidade da linhaça reduzir o ganho de peso parece também estar associada ao fato de que a ingestão proporciona a eliminação do colesterol em forma rápida. Além disso, ajuda a controlar a obesidade e a sensação desnecessária de apetite, por conter grandes quantidades de fibra dietética (Pan \& Storlien, 1993; Wang et al., 2002).

Dentre as inúmeras causas que vêm sendo apontadas para o aumento da obesidade entre crianças e adultos no mundo estão a mudança qualitativa dos ácidos graxos ingeridos. $O$ aumento do consumo de AG- $\omega 6$ (principalmente, Ácido Linoléico - $A L$ ) com concomitante redução dos AG$\omega 3$ (principalmente, ALA), levando a aumento da relação $A G \omega 6 / A G \omega 3$, tem sido apontado como importante agente obesogênico (Pan \& Storlien, 1993; Aailhaud et al., 2006). Portanto, o estímulo para o aumento do consumo de fontes alimentícias ricas em AG-ù3, como é o caso da linhaça e derivados, parece poder contribuir de forma positiva para a redução dos índices de obesidade na população mundial.

Considerando que dentre os critérios propostos pelo NCEP-ATPIII (2001), para a prevenção dos fatores de risco para DCV estão a redução dos níveis séricos de CT e aumento dos níveis séricos de HDL-C, com base nos resultados obtidos neste estudo, acredita-se poder recomendar o uso da linhaça e derivados, em quantidades adequadas, como suplemento dietético tanto para a prevenção de DCV quanto como coadjuvante na prevenção e tratamento da obesidade.

Os resultados obtidos neste estudo contribuem para melhor entendimento do papel da linhaça como alimento funcional, sendo possível esclarecer algumas diferenças em relação aos efeitos da farinha de linhaça marrom e dourada.

Foi observado que, apesar da farinha de linhaça dourada promover efeito superior em relação a farinha marrom na redução dos níveis de triglicérides e aumento do HDL-c, ambas apresentaram importante papel na melhoria do perfil lipídico dos animais investigados, quando comparadas com os animais controle. Os efeitos sobre o ganho ponderal dos animais durante o período do experimento indicaram importante ação preventiva no desenvolvimento da obesidade das duas farinhas testadas.

Estes resultados sugerem que o consumo da farinha de linhaça marrom, produzida no Brasil e vendida a preços bem mais acessíveis do que a farinha dourada, deve ser incentivado na população para que a incidência de doenças crônicas como a obesidade, a dislipidemia e outras doenças cardiovasculares sejam reduzidas.

Pesquisas adicionais necessitam ser feitas com o intuito de identificar quais componentes da farinha de linhaça estão efetivamente exercendo cada um dos efeitos observados, se há algum tipo de interação entre eles, bem como, quais as quantidades mínimas necessárias para alcançar os efeitos desejados e quais as quantidades máximas que possam vir a ser utilizadas sem causar quaisquer riscos à saúde.

Rev. Bras. Pl. Med., Botucatu, v.12, n.2, p.201-207, 2010. 


\section{REFERÊNCIA}

AAILHAUD, G. et al. Temporal changes in dietary fats: Role of n- 6 polyunsaturated fatty acids in excessive adipose tissue development and relationship to obesity. Progress in Lipid Research, v.45, n.3, p.203-36, 2006. ARTERBURN, L.M.; HAL, E.B.; OKEN, H. Distribution, interconversion, and dose response of $n-3$ fatty acids in humans. American Journal of Clinical Nutrition, v.83, n.6, p.1467-76, 2006.

BALK, E.M. et al. Effects of omega-3 fatty acids on serum markers of cardiovascular disease risk: A systematic review. Atherosclerosis, v.189, n.1, p.19-30, 2006.

BHATENA, S.J.; VELAZQUEZ, M.T. Beneficial role of dietary phytoestrogens in obesity and diabetes. American Journal of Clinical Nutrition, v.76, n.6, p.1191-201, 2002. BRASIL. Resolução RDC no 263, de 22 de setembro de 2005. Aprova o "Regulamento técnico para produtos de cereais, amidos, farinhas e farelos". Diário Oficial da União, Brasília, 23 set. 2005. Disponível em: <http:// elegis.anvisa.gov.br/leisref/public/ showAct.php?id= 18822\&word=>. Acesso em: 15 jan. 2009.

CINTRA, D.E.C. Lipid profile of rats fed high-fat diets based on flaxseed, peanut, trout, or chicken skin. Nutrition, v.22, n.2, p.197-205, 2006.

CONNOR, W.E. Importance of n-3 fatty acids in health and disease. American Journal Clinical Nutrition, v.7, n.1, p.171-5, 2000.

COSKUNER, Y.; KARABABA, E. Some physical properties of flax seed (Linum usitatissimum L.). Journal of food Engineering, v.78, n.3, p.1067-73, 2007.

DDODIN, S. et al. Flaxseed on cardiovascular disease markers in healthy menopausal women: a randomized, doublé-blind, placebo-controlled trial. Nutrition, v.24, n.1, p.23-30, 2008.

FENG, D.; SHEN, Y.; CHAVEZ, E.R. Effectiveness of different processing methods in reducing hydrogen cyanide content of flaxseed. Journal Science of Food and Agriculture, v.83, n.8, p.836-41, 2003.

HEMMINGS, S.J.; BARKER, L. The effects of dietary flaxseed on the Fischer 344 rat: Development, behaviour, toxicity and the activity of liver gammaglutamyltranspeptidadese. Cellular Biochemic Function, v.22, n.6, p.113-21, 2004.

KINNIRY, P. et al. Dietary flaxseed supplementation ameliorates inflammation and oxidative tissue damage in experimental models of acute lung injury in mice. Journal of Nutrition, v.136, n.6, p.1545-51, 2006.

MEYDANI, S.N. Effect of (n-3) polyunsaturated fatty acids on cytokine production and their biologic function.
Nutrition, v.12, n.1, p.8-14, 1996.

MOREIRA, R.O. et al. Perfil lipídico de pacientes com alto risco para eventos cardiovasculares na prática clínica diária. Arquivos Brasileiros de Endocrinologia e Metabologia, v.50, n.3, p.481-9, 2006.

MORISE, A. Effects of dietary alfa linolenic acid on cholesterol metabolism in male and female hamster of the LPN strain. Journal of Nutrition Biochemics, v.15, n.1, p.51-61, 2004.

NAGAO, K.; YANAGITA, T. Bioactive lipids in metabolic syndrome. Progress in Lipid Research, v.47, n.2, p.127-46, 2008.

NATIONAL CHOLESTEROL EDUCATION PROGRAM. Executive Summary of the Third Report of the National Cholesterol Education Program (NCEP) Expert Panel on Detection, Evaluation, and Treatment of High Blood Cholesterol in Adults (Adult Treatment Panel III). JAMA, v.285, n.2, p.2486-97, 2001.

OOMAH, B.D. Flaxseed as a functional food source. Journal of Science and Food Agriculture, v.81, n.9, p.889-94, 2001. PAN, D.A.; STORLIEN, L.H. Dietary lipid profile is a determinant of tissue phospholipid fatty acid composition and rate of weight gain in rats. Journal Nutrition, v.123, n.3, p.512-9, 1993.

PELLIZZON, M.A. et al. Flaxseed reduces plasma cholesterol levels in hypercholesterolemic mouse models. American Journal of Clinical Nutrition, v.26, n.1, p.66-75, 2007.

PRASAD, K. Secoisolariciresinol diglucoside from flaxseed delays the development of type 2 diabetes in Zucker rat. Journal of Laboratorial and Clinical Medicine, v.138, n.1, p.32-9, 2001.

PRASAD, K. Hypocholesterolemic and antiatherosclerotic effect of flax lignan complex isolated from flaxseed. Atherosclerosis, v.179, n.2, p.269-75, 2005.

TRUCOM, C. A importância da linhaça na saúde. São Paulo: Alaúde, 2006. 152p.

VIJAIMOHAN, K. et al. Beneficial effects of alpha linolenic acid rich flaxseed oil on growth performande and hepatic cholesterol metabolism in high fat diet fed rats. Life Sciences, v.79, n.5, p.448-54, 2006.

WANG, H.; STORLIEN, L.H.; HUANG, X.F. Effects of dietary fat types on body fatness, leptin, and ARC leptin receptor, NPY, and AgRP mRNA expression. American Journal Physiology and Endocrinology Metabolic, v.282, n.6, p.1352-9, 2002.

WORLD HEALTH ORGANIZATION - WHO. Nutrition. Science - Policy. WHO and FAO Joint Consultation: fats and oils in human nutrition. Nutrition Reviews, v.53, n.7, p.202-5, 1995. 